Document downloaded from:

http://hdl.handle.net/10251/84097

This paper must be cited as:

Stefanidis, S.; Kalogiannis, K.; lliopoulou, EF.; Lappas, AA.; Martínez Triguero, LJ.; Navarro Ruiz, MT.; Chica, A.... (2013). Mesopore-modified mordenites as catalysts for catalytic pyrolysis of biomass and cracking of vacuum gasoil processes. Green Chemistry. 15(6):1647-1658. doi:10.1039/c3gc40161h

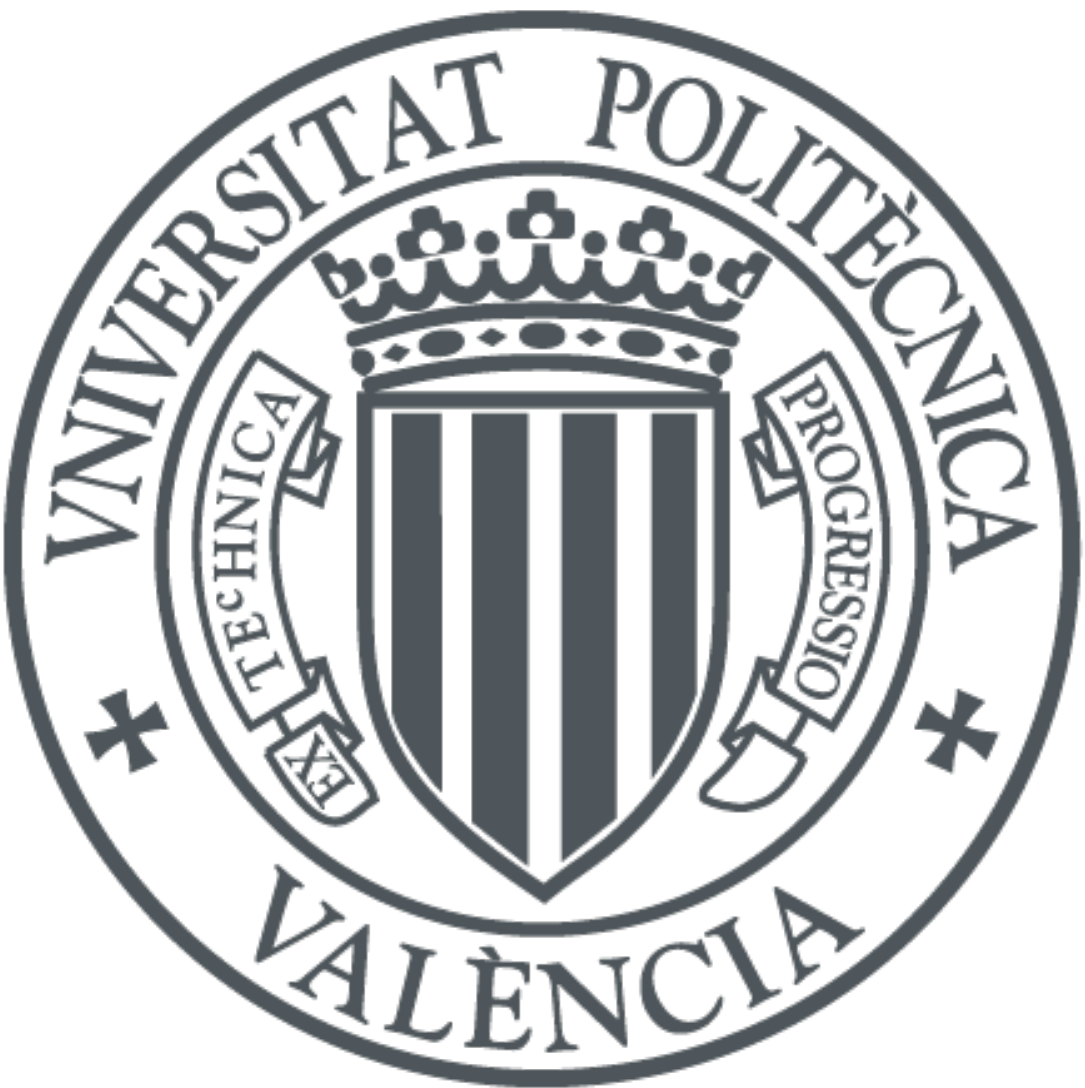

The final publication is available at

http://dx.doi.org/10.1039/c3gc40161h

Copyright Royal Society of Chemistry

Additional Information 
See discussions, stats, and author profiles for this publication at: https://www.researchgate.net/publication/236644982

\section{Mesopore-modified mordenites as catalysts for catalytic pyrolysis of biomass and cracking of vacuum gasoil processes}

Article in Green Chemistry · April 2013

DOI: 10.1039/c3gc40161h

\section{CITATIONS}

26

8 authors, including:

Stylianos D. Stefanidis

Aston University

27 PUBLICATIONS 872 CITATIONS

SEE PROFILE

2. Joaquin Martinez Triguero

Universitat Politècnica de València

43 PUBLICATIONS 1,643 CITATIONS

SEE PROFILE

Some of the authors of this publication are also working on these related projects:

tubulAir - tubular Vanadium/Air Redox Flow Battery View project

Project Structural studies of zeolites View project
Konstantinos G. Kalogiannis

The Centre for Research and Technology, Hellas

40 PUBLICATIONS 1,036 CITATIONS

SEE PROFILE 


\title{
Mesopore-modified Mordenites as catalysts for catalytic pyrolysis of biomass and cracking of vacuum gas oil processes
}

\author{
S. Stefanidis ${ }^{1,2}$, K. Kalogiannis ${ }^{1}$, E.F. Iliopoulou ${ }^{1, *}$, A.A. Lappas ${ }^{1}$,

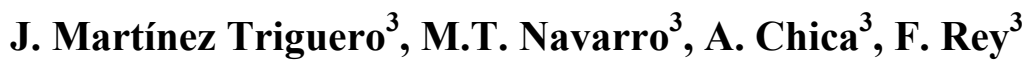 \\ ${ }^{1}$ Chemical Process \& Energy Resources Institute, CERTH, P.O. Box 60361 \\ Thermi, 57001 Thessaloniki, Greece \\ ${ }^{2}$ Department of Mechanical Engineering, University of Western Macedonia, \\ 50100 Kozani, Greece \\ ${ }^{3}$ Instituto de Tecnologia Química, UPV-CSIC, Avda. de los Naranjos s/n, 46022 \\ Valencia, Spain
}

*corresponding author'se-mail:eh@cperi.certh.gr 


\begin{abstract}
Mesopore-modified Mordenite zeolitic materials with different $\mathrm{Si} / \mathrm{Al}$ ratios have been prepared and tested in the biomass pyrolysis and catalytic cracking of vacuum gasoil. Alkaline treatment was carried out to generate mesoporosity. Severity of alkaline treatment was found of paramount importance to tune the generated mesoporosity, while it significantly affected the crystallinity of treated mordenites. It was moreover observed that the alkaline treatment selectively extracted $\mathrm{Si}$ decreasing the $\mathrm{Si} / \mathrm{Al}$ ratio of treated samples. Catalytic activity of parent and alkaline treated mordenites was studied in the pyrolysis of biomass. All zeolitic based materials produced less amounts of bio-oil but of better quality (lowering oxygen content from $\sim 40 \%$ to as much as $21 \%$ ) as compared to the non-catalytic pyrolysis experiments. On the other hand, it was found that the combination of mesopore formation and high surface area after alkaline treatment of the mordenite with high $\mathrm{Si} / \mathrm{Al}$ ratio resulted in the enhancement of its catalytic activity, despite the reduction of its acidity. The increment of the decarboxylation and dehydration reactions, combined with a reduction of carbon deposition on the catalyst, resulted in a remarkable decrease in the oxygen content in the organic fraction and therefore, resulted in a superior quality liquid product. Alkaline treated mordenites were additionally acid treated targeting dealumination and removal of the extraframework debris, thus generating mesopore-modified mordenite samples with stronger acid sites and higher total acidity, as candidate catalysts for catalytic cracking of vacuum gasoil. Desilicated and especially desilicated and dealuminated mordenites exhibited the highest activity and selectivity towards LCO with the best olefinicity in gases and higher bottoms conversion. Therefore, an optimized desilicated-dealuminated mordenite additive could be an interesting candidate as component of the FCC catalyst for high LCO yield.
\end{abstract}

Keywords: lignocellulosic wood biomass, catalytic biomass flash pyrolysis, bio-oil, zeolites, mordenite, mesoporosity, cracking, vacuum oil. 


\section{Introduction}

It is well known that biomass can be transformed into liquid fuels through the process of pyrolysis, which is in essence the thermal degradation of the organic material in the absence of oxygen [1]. The applicability of bio-oil from biomass is limited by its water content, elevated concentration of oxygenated molecules, high acidity and thermal instability [2]. Catalytic pyrolysis of biomass by the use of various catalysts has been introduced in order to improve the quality of the final bio-oil mainly through deoxygenation reactions [3-5]. In this regard, acid catalysts have been primarily studied in the transformation of bio-oils with the aim to remove the oxygen content of these molecules [6-8]. The main problem during deoxygenation reaction is the deactivation of these catalysts due to coke formation. Coking is attributed to the condensation of phenolic components, especially those of high molecular weight, which can make up to $30 \mathrm{wt}$. \% of the liquid pyrolysis (based on biomass feed) $[9,10]$. In addition, the components of bio-oil have large molecular volume, which inhibit their diffusion to the active sites located inside the zeolite pores, obstructing processing and deoxygenation of the bio-oil.

In order to enhance the accessibility, the molecular transport and to avoid the pore blockage by coke deposition, mesoporosity formation in the zeolites seems a promising approach. The presence of mesopores in the crystalline framework of the zeolite would be equivalent to increasing its external surface, making a larger number of pore openings accessible to the large reactants. Corma evidenced the beneficial effect of the combination of micro and mesoporous region in the zeolite comparing the cracking activity of two series of $\mathrm{Y}$ zeolite samples, dealuminated by $\mathrm{SiCl}_{4}$ and steam [11]. The steam-dealuminated samples contained a greater proportion of mesoporosity and gave higher conversion. It was clear that the increased accessibility to the acid sites through generation of mesopores had a positive impact on their catalytic performance, especially when large molecules were processed. Enhanced performance was observed, even though these zeolites were severely dealuminated during steaming, exhibiting therefore lower concentration of acid sites.

Mesoporosity in zeolites can be also created through a process called desilication, which consists of a controlled extraction of silicon from the framework, treating the zeolite in alkaline medium. This treatment produced extended mesoporosity in zeolites crystals, with minor effect on their acidity [12,13]. Several publications on this subject have recently emerged, especially focusing on MFI and MOR type zeolite [14-17]. 
Considering that catalytic reactions involving large molecules, take place mainly at the pore mouth $[18,19]$, a large fraction of the active sites in zeolites would be inaccessible. Desilication treatment could be a good option, increasing accessibility of acid sites through the generation of mesopores, while preserving at the same time acid sites. Mesoporous zeolites obtained by desilication in basic medium have been studied in the catalytic cracking of pure compounds, naphtha and polymers leading to an important increase in activity due to the enhanced accessibility [20]. Park et al. [21] studied the application of hierarchical MFI zeolites obtained by synthesis with organosilanes in the cracking of VGO showing higher activity and selectivity to gasoline. Current application of mordenites (MOR) in FCC is limited due to diffusional limitations. Formation of mesopores would facilitate their use both increasing accessibility and improving selectivity to middle distillates.

A mesoporous MFI catalyst, a new material with the advantages of both zeolite catalysts and mesoporous materials was synthesized using a mesopore directing agent and was also recently evaluated in the catalytic upgrading of miscanthus-derived bio-oil showing the highest activity for the deoxygenation and aromatization, among all catalysts tested in this study (Al-MCM-41, Al-MCM-48, HZSM-5) [22]. The effect of modifying the bulk silica-toalumina ratio in ZSM-5, incorporating hierarchical mesopores, and selectively removing external surface acid sites was also investigated on the activity and selectivity of biomass conversion during catalytic fast pyrolysis (CFP) of glucose, furan, and maple wood. Creating hierarchical mesopores within the zeolite slightly increased coke formation and decreased the formation of the monocyclic aromatics, also favouring the production of larger alkylated monoaromatics. The selective removal of external acid sites from the ZSM-5 catalysts only slightly increased the catalyst activity but also decreased the selectivity to the desired aromatic products [23]. Novel hierarchical cerium incorporated HZSM-5 catalysts, were investigated in the catalytic fast pyrolysis of glucose and exhibited high coke reduction and a shift from the formation of BTX (benzene, toluene, xylenes) to oxygenated chemicals, when compared to cerium-loaded control materials prepared by incipient wetness impregnation and by ion-exchange. These catalysts were also reported to perform $\mathrm{C}-\mathrm{C}$ bond formation reactions between carboxylic acids via ketonization [24]. Finally, Meso-MFI and Pt-Meso-MFI were used and evaluated for the first time for the catalytic pyrolysis of rice husk. The yield of oxygenates that can degrade the quality of the produced bio-oil was reduced due to catalytic upgrading, by $38 \%$ with Meso-MFI and by $49 \%$ with Pt-Meso-MFI, demonstrating the outstanding activity of the Pt-Meso-MFI catalyst in deoxygenation. Moreover, Meso-MFI exhibited a good selectivity for aromatics, which is ascribed to its strong acid sites and shape 
selectivity due to the MFI structure. Pt-Meso-MFI was even more effective in the upgrading of bio-oil because of the additional catalytic effect of Pt [25].

In the present work, modified mordenite zeolites with controlled acid sites and mesoporosity were prepared and the influence of the several desilication parameters $(\mathrm{NaOH}$ concentration, temperature and time) on the structural, textural and acidic properties was studied. In addition, the more stable mesopore-modified mordenite samples were tested as candidate catalytic materials in the lignocellulosic biomass pyrolysis process, a known, interesting route for the valorisation of this renewable source towards production of liquid fuels. Besides that, the modified mordenite zeolites were also tested in the catalytic cracking of vacuum oil, considering that the generated mesopores will improve the activity and selectivity of these zeolites, when molecules with large volume are processed.

\section{Experimental}

\subsection{Mordenite zeolites}

Two commercial Mordenites (purchased from Zeolyst Intl.) with different nominal Si/Al ratios of 5 (CBV10) and 10 (CBV20) were employed as parent materials. The catalytic materials were used as received and were subjected to an alkaline solution treatment to create mesoporosity [26]. They were subsequently acid treated for dealumination and removal of the extraframework debris formed during the alkaline treatment. The resulting zeolites were acquired in the ammonium form and were transformed in their acid counterparts by calcination at $773 \mathrm{~K}$ in air for 12 hours.

\subsubsection{Alkaline treated mordenites}

The severity of the desilication treatment was initially studied on the parent acidic Mordenites samples. The general alkaline treatment was as follows: 5 grams of ammonium form-zeolite were added on $150 \mathrm{ml}$ pre-heated alkaline solution of a given concentration, at different temperatures, for 30 minutes, under continuous stirring. The alkaline treated-zeolite was recovered by filtration and washed with hot distilled water, until neutral $\mathrm{pH}$. The derived samples were recovered in the inactive $\mathrm{Na}$-form, and thus were subsequently transformed into their acid counterparts by double ion exchange treatment in an aqueous $2.5 \mathrm{M} \mathrm{NH}_{4} \mathrm{Cl}$ solution at $353 \mathrm{~K}$ for $2 \mathrm{~h}$, followed by calcination at $773 \mathrm{~K}$ in air for $3 \mathrm{~h}$. The specific conditions of the desilication procedures employed are given in Table 1. 
Table 1. Conditions of alkaline treatments

\begin{tabular}{ccc}
\hline Alkaline treatment & NaOH solution $(\mathrm{mol} / \mathrm{l})$ & Temperature $(\mathrm{K})$ \\
\hline D1 & 0.2 & 353 \\
D2 & 1 & 353 \\
D3 & 3 & 353 \\
D4 & 0.2 & 298 \\
D5 & 0.2 & 273 \\
\hline
\end{tabular}

\subsubsection{Acid treated mordenites}

Desilicated mordenites were also submitted to acid treatments for removal of the extra framework debris formed during the previous alkaline treatment, as well as for dealumination of the mordenite treated materials. The acid treatments were performed on the alkaline desilicated materials prior to the ammonium exchange steps, i.e. the Na-form zeolite was treated with a aqueous solution of $\mathrm{HNO}_{3}$, with a given concentration, at different temperatures for 1 hour, under continuous stirring. The specific conditions of the acid treatments are given in Table 2.

Table 2. Conditions of acid treatments

\begin{tabular}{ccc}
\hline Acid treatment & $\mathrm{HNO}_{3}$ solution (Molar) & Temperature (K) \\
\hline A1 & 3 & 298 \\
A2 & 3 & 373 \\
A3 & 13 & 373 \\
\hline
\end{tabular}

\subsection{Characterization of catalytic materials}

ICP-AES was used for the determination of the chemical composition (wt. \% of $\mathrm{Si}, \mathrm{Al}$ and $\mathrm{Na}$ ) of the catalytic materials, using an ICP optical Emission Spectrometer Varian 715$\mathrm{ES}$, The solution for the ICP-AES analysis was prepared by digesting at $213 \mathrm{~K} \mathrm{ca} .0 .03 \mathrm{~g}$ of mordenite powder in a solution obtained by mixing $1 \mathrm{cc}$ of $40 \mathrm{wt} \% \mathrm{HF}, 3 \mathrm{cc}$ of $\mathrm{HCl}$ of $37 \mathrm{wt} \%$ and $1 \mathrm{cc}$ of $63 \mathrm{wt} \% \mathrm{HNO}_{3}$. After digestion, the solution was diluted with distilled water to the desired concentration.

Powder X-ray diffraction (XRD) was used for the verification of the crystallinity of the zeolite catalysts. The patterns were collected using a Panalytical X'Pert Pro diffractometer, operating at $40 \mathrm{kV}$ and $45 \mathrm{~mA}$ and employing nickel-filtered $\mathrm{Cu} \mathrm{K} \alpha$ radiation $(\lambda=0.1542$ $\mathrm{nm}$ ). $\mathrm{N}_{2}$ adsorption/desorption isotherms at $77 \mathrm{~K}$ using a Micromeritics apparatus (ASAP2020) were used for the determination of the porosity properties of the catalytic materials. Prior to the measurement, the samples were degassed in high-vacuum at $673 \mathrm{~K}$ for $10 \mathrm{~h}$, being 
the final pressure lower than $10^{-5}$ mbar. The Brunauer-Emmett-Teller (BET) and Langmuir methods [27] were applied to calculate the total surface area, which is used for comparative purposes. The t-plot [28] method was used to discriminate between micro- and mesoporosity. The pore size distribution was obtained by applying the Barret-Joyner-Halenda modified by Kruk, Jaroniec and Sayari (BJH-KJS) model [29] to the adsorption branch of the isotherm.

FT-IR spectroscopy combined with step-wise desorption of pyridine was used for the determination of the Brönsted and Lewis type acid sites of the catalysts, using a Nicolet 710 FTIR apparatus following the experimental procedure detailed in [30]. The amount of Brönsted and Lewis acid sites was determined from the integrated areas of the bands at ca. $1545 \mathrm{~cm}^{-1}$ and $1450 \mathrm{~cm}^{-1}$, respectively, using the extinction coefficients obtained by Emeis [31].

Finally, transmission electron microscopy (TEM), using a Philips CM-10 microscope operating at $100 \mathrm{kV}$ was used for in depth investigation of crystallinity changes (loss of crystallinity, decrease in average crystal domain etc) as a result of the mesporosity formation. The samples under investigation were initially ultrasonically dispersed in 2-propanol and then transferred to carbon coated copper grids.

\subsection{Biomass feedstock properties}

The biomass used in this study was a commercial lignocellulosic biomass (Lignocel HBS 150-500) originating from beech wood. The properties of the biomass feedstock are shown in Table 3. The ash content of biomass was measured with a method similar to the ASTM E1755-01 and was determined as the solid residue after dry oxidation of biomass in air at 873 $\mathrm{K}$ for $16 \mathrm{~h}$. The moisture was determined by drying at $375 \mathrm{~K}$ for $4 \mathrm{~h}$. Carbon and Hydrogen $(\mathrm{C}$ and $\mathrm{H})$ content was determined by elemental analysis using a LECO-800 CHN analyser.

Table 3. Properties of biomass feedstock (Lignocel HBS 150-500, beech wood)

\begin{tabular}{|l|r|}
\hline Ash/solid residue (dry wt. \%) & 0.66 \\
\hline C (dry wt. \%) & 45.98 \\
\hline H (dry wt. \%) & 6.39 \\
\hline O (dry wt. \%, determined by difference) & 46.97 \\
\hline Moisture (wt. \%) & 8.25 \\
\hline
\end{tabular}

\subsection{Biomass flash pyrolysis (non-catalytic and catalytic) experiments}

All pyrolysis experiments were performed at $773 \mathrm{~K}$, using a bench-scale fixed bed reactor, made of stainless steel 316 and heated by a 3-zone furnace. The temperature of each 
zone was independently controlled using temperature controllers. The catalyst bed temperature was considered as the experiment temperature and was monitored with a thermowell. A specially designed piston system was used to introduce the biomass feedstock into the reactor. A constant stream of $\mathrm{N}_{2}$ was fed from the top of the reactor for the continuous withdrawal of the products and maintenance of an inert atmosphere during pyrolysis. The products exited from the bottom of the reactor in gaseous form and were condensed in a glass receiver submerged in a cooling bath that was kept at $256 \mathrm{~K}$. Noncondensable gases were collected in a gas collection system. A filter placed between the glass receiver and the gas collection system recovered any condensable gases that were not condensed in the receiver. A typical residence time of the vapour phase in the catalyst bed was about $0.03 \mathrm{sec}$. Non-catalytic pyrolysis experiments, with the use of inert silica sand instead of the catalytic materials, were also performed for comparison. The above described catalytic pyrolysis experiments can be referred to as in situ upgrading of pyrolysis vapours and are of the "ex-bed" type (i.e. there was no mixing of solid biomass with the solid catalyst). In addition, all the experimental parameters (i.e., fast heating of biomass, low residence time, fast cooling of products) resemble those of the biomass fast pyrolysis (BFP) type of experiments.

The liquid products were collected and quantitatively measured in the pre-weighted glass receiver. The pyrolytic vapours, upon their condensation in the glass receiver, formed multiple phases; an aqueous phase, a liquid organic phase and viscous organic deposits on the receiver walls. Extensive effort has been put in the development of a method for the collection of a representative bio-oil sample for analysis. Towards this goal, the bio-oil was first fully homogenized inside the receiver using ethyl lactate as the solvent and then collected as a solution, which was then submitted for analysis. Ethyl lactate was chosen for its nonvolatility, which minimizes errors during weighing. It also proved to be a good solvent for all the bio-oil samples in this study.

The water content of the bio-oil was determined by the Karl-Fischer method (ASTM E203-08). The water/aqueous phase present in the bio-oil was separated from the organic phase using an organic solvent (dichloromethane). The organic phase of the bio-oil was analysed by GC-MS using an Agilent 7890A/5975C gas chromatograph-mass spectrometer system (Electron energy $70 \mathrm{eV}$, Emission $300 \mathrm{~V}$, Helium flow rate: $0.7 \mathrm{cc} / \mathrm{min}$, Column: HP$5 \mathrm{MS} 30 \mathrm{~m} \times 0.25 \mathrm{~mm}$ ID $\times 0.25 \mu \mathrm{m}$ ). Internal libraries were used for the identification of the compounds found in the bio-oil and their categorization into main functional groups. The gaseous products were collected inside a container filled with oil and measured by the water 
displacement method (as the gases filled the container, the oil was pushed out inside a volumetric cylinder and the total volume of the produced gases was determined as the total volume of the pushed out oil). The gaseous products were analysed in a HP 5890 Series II gas chromatograph, equipped with four columns (Precolumn: OV-101, Columns: Porapak N, Molecular Sieve 5A and Rt-Qplot $30 \mathrm{~m} \times 0.53 \mathrm{~mm} \mathrm{ID)}$ and two detectors (TCD and FID). The amount of the solid residue left in the reactor and deposited on the catalyst surface, consisted mainly of charcoal and coke-on-catalyst formed by thermal and/or catalytic cracking and was determined by direct weighting.

\subsection{Catalytic cracking of gasoil}

Catalytic cracking of vacuum gasoil was performed in a Microactivity Test Unit following the procedure described in the literature $[30,32]$. The reaction gases $\left(\mathrm{H}_{2}, \mathrm{CO}, \mathrm{CO}_{2}\right.$, $\mathrm{H}_{2} \mathrm{~S}$ and $\mathrm{C}_{1}$ to $\mathrm{C}_{4}$ hydrocarbons) were analysed by gas chromatography in a rapid refinery gas analyser from Bruker (450-GC). Simulated distillation in a Bruker SIMDIS was also performed. The catalyst samples were pelletized $(0.5-0.8 \mathrm{~mm})$ and mixed with pure silica $(0.5$ $\mathrm{g}$ of zeolite $-2.5 \mathrm{~g}$ of silica). The properties of vacuum gasoil used were described elsewhere $[32]$.

\section{Results and Discussion}

\subsection{Physicochemical characteristics of zeolitic catalysts before and after alkaline treatment}

The chemical composition and textural properties of the parent and alkaline-treated MOR zeolites, in their protonic form, are summarized in Table 4 . The acidity of the parent zeolites and the optimal desilicated zeolites was studied by the FTIR-pyridine step-wise desorption technique. The quantitative results on acid properties of the alkaline treated mordenite samples obtained are presented in Table 5. In addition, the XRD patterns of all zeolites (treated samples and their corresponding parent materials) are shown in Figures 1 and 2.

The results shown in Table 4 and Figures 1 and 2 clearly indicate that the crystallinity of the Mordenite samples was mostly retained, as evidenced by the relatively low decrease of the $\mathrm{X}$-Ray diffraction peaks, as well as the micropore volume values. Only the most severe treatments decreased the crystallinity of the sample by $25 \%$ (averaged micropore volume of Mordenite samples decreased from $0.19 \mathrm{~cm}^{3} / \mathrm{g}$ to $0.14 \mathrm{~cm}^{3} / \mathrm{g}$ ), while it was practically unaffected by the softer alkaline treatments. It must be pointed out however, that the parent Mordenite sample having the lowest $\mathrm{Si} / \mathrm{Al}$ ratio (CBV10) was much more stable than the high 
silica material (CBV20) towards alkaline treatment, as clearly evidenced in Table 4 and Figures 1 and 2. Moreover, both parent mordenites present very similar Brönsted acidity despite the different $\mathrm{Si} / \mathrm{Al}$ ratio. CBV10 having higher aluminium content presents much higher concentration of Lewis acid sites, attributed to the instability of part of the framework aluminium during ammonium exchange and calcination treatments. The $\mathrm{Si} / \mathrm{Al}$ ratios of the alkaline-treated Mordenites decreased as the severity of the treatment increased, indicating that the alkaline media selectively extracted $\mathrm{Si}$ instead of $\mathrm{Al}$, resulting in lower $\mathrm{Si} / \mathrm{Al}$ ratio Mordenites samples.

Table 4. Textural properties and chemical compositions of the parent and alkaline-treated mordenites samples.

$\begin{array}{lccccc}\text { Catalyst } & \begin{array}{c}\text { Molar } \\ (\mathrm{Si} / \mathrm{Al})^{\mathrm{a}}\end{array} & \begin{array}{c}\mathrm{V}_{\mathrm{MICRO}}^{\mathrm{b}} \\ \left(\mathrm{cm}^{3} / \mathrm{g}\right)\end{array} & \begin{array}{c}\mathrm{V}_{\mathrm{MESO}}{ }^{\mathrm{c}} \\ \left(\mathrm{cm}^{3} / \mathrm{g}\right)\end{array} & \begin{array}{c}\text { BET } \\ \text { Surface Area } \\ \left(\mathrm{m}^{2} / \mathrm{g}\right)\end{array} & \begin{array}{c}\text { Langmuir } \\ \text { Surface Area } \\ \left(\mathrm{m}^{2} / \mathrm{g}\right)\end{array} \\ \text { CBV10 } & 6.5 & 0.203 & 0.043 & 440 & 592 \\ \text { CBV10-D1 } & 6.0 & 0.192 & 0.059 & 427 & 576 \\ \text { CBV10-D2 } & 5.9 & 0.196 & 0.075 & 438 & 585 \\ \text { CBV10-D3 } & 3.8 & 0.145 & 0.101 & 348 & 467 \\ \text { CBV20 } & 10.0 & 0.182 & 0.10 & 433 & 583 \\ \text { CBV20-D1 } & 8.1 & 0.180 & 0.195 & 481 & 646 \\ \text { CBV20-D2 } & 5.0 & 0.147 & 0.234 & 488 & 665\end{array}$

${ }^{\mathrm{a}}$ ICP analyses; ${ }^{\mathrm{b}}$ t-plot method; ${ }^{\mathrm{c}}$ BJH-KJS Adsorption pore volume between 1.7 and $30 \mathrm{~nm}$.

Table 5. Acidity of parent zeolites and optimal desilicated zeolites.

\begin{tabular}{|c|c|c|c|c|c|c|c|}
\hline \multirow[t]{2}{*}{ Samples } & \multirow[t]{2}{*}{$\mathrm{Si} / \mathrm{Al}$} & \multicolumn{3}{|c|}{$\begin{array}{l}\text { Brönsted Acidity } \\
(\mathrm{mmoles} P y / g)^{\mathrm{a}}\end{array}$} & \multicolumn{3}{|c|}{$\begin{array}{l}\text { Lewis Acidity } \\
(\mathrm{mmoles} P y / g)^{\mathrm{a}}\end{array}$} \\
\hline & & $523 \mathrm{~K}$ & $623 \mathrm{~K}$ & $673 \mathrm{~K}$ & $523 \mathrm{~K}$ & $623 \mathrm{~K}$ & $673 \mathrm{~K}$ \\
\hline CBV10 & 6.5 & 0.419 & 0.309 & 0.176 & 0.104 & 0.099 & 0.094 \\
\hline CBV10-D3 & 3.8 & 0.113 & 0.080 & 0.053 & 0.045 & 0.045 & 0.043 \\
\hline CBV20 & 10.0 & 0.477 & 0.389 & 0.262 & 0.080 & 0.080 & 0.073 \\
\hline CBV20-D1 & 8.1 & 0.264 & 0.165 & 0.155 & 0.060 & 0.055 & 0.047 \\
\hline CBV20-D2 & 5.0 & 0.226 & 0.099 & 0.049 & 0.145 & 0.085 & 0.051 \\
\hline
\end{tabular}




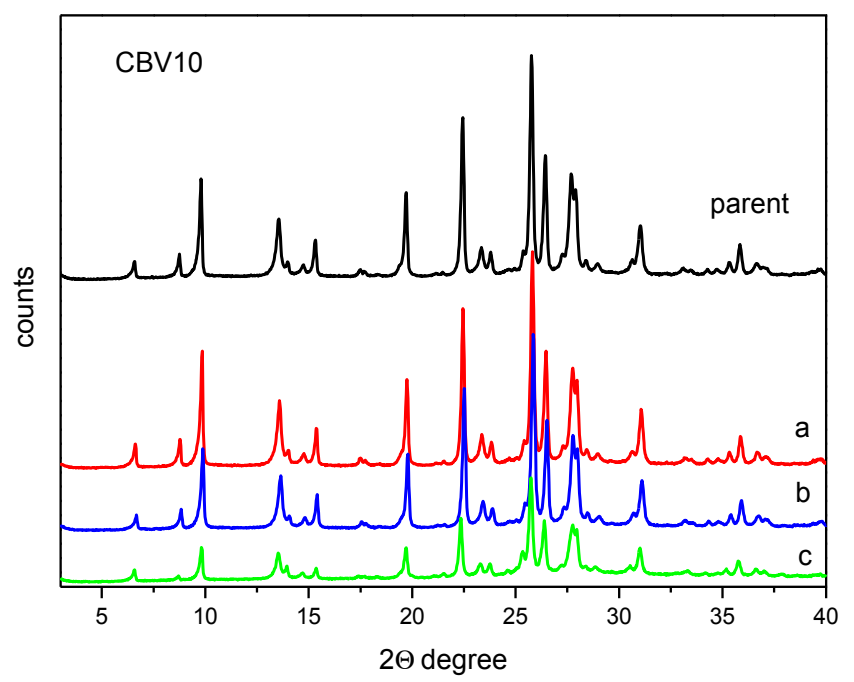

Figure 1. X-Ray Diffraction patterns of CBV10 zeolites: parent and alkaline treated samples.

(a) CBV10-D1, (b) CBV10-D2, (c) CBV10-D3.

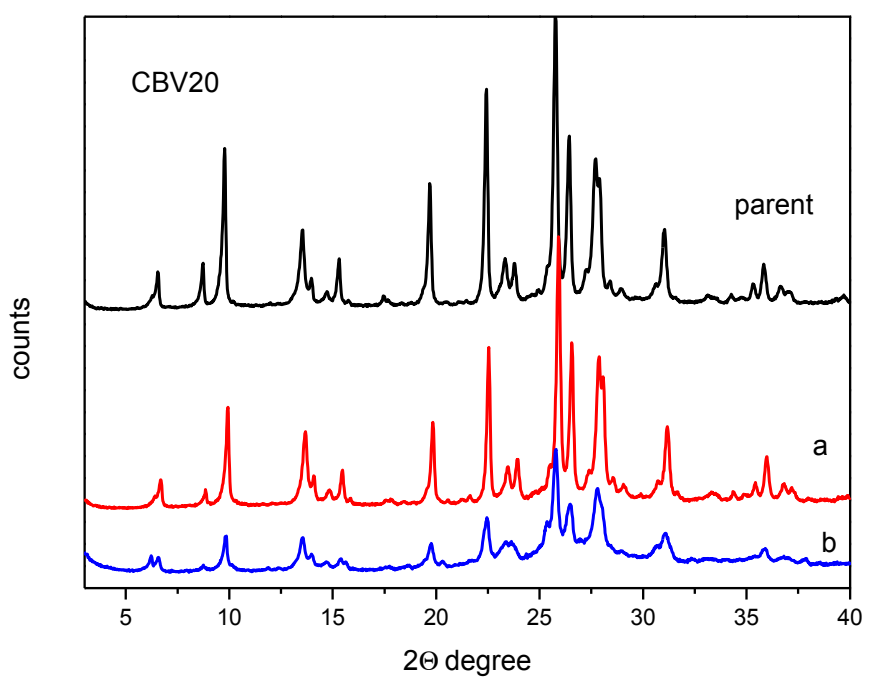

Figure 2. X-Ray Diffraction patterns of CBV20 zeolites: parent and alkaline treated samples.

(a) CBV20-D1, (b) CBV20-D2.

The formation of mesoporosity is clearly seen in the TEM images, provided in Figure 3, where the original CBV20 mordenite sample is compared to the treated alkaline materials. The formation of large 'pores' was observed, which were not present in the parent material. 
The size and number of these newly formed mesopores increased as the severity of the alkaline treatment increased.

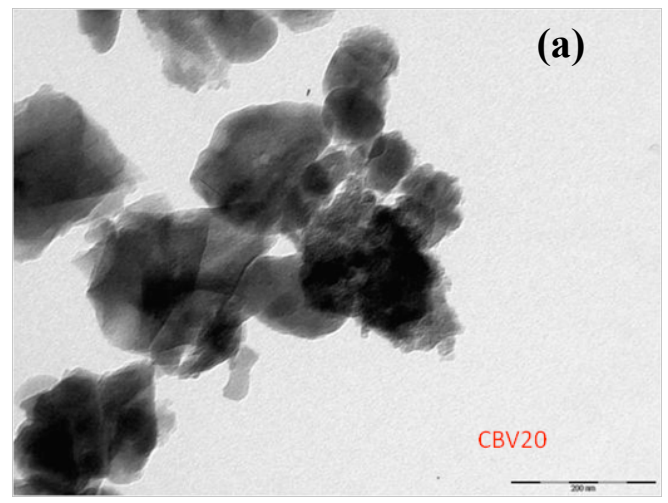

(b)

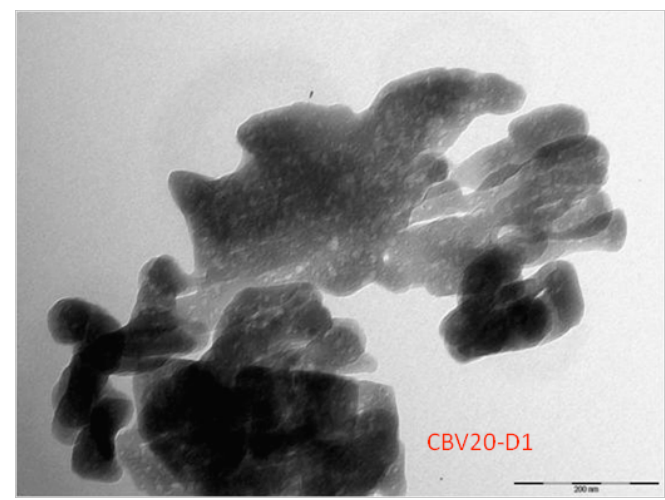

(c)

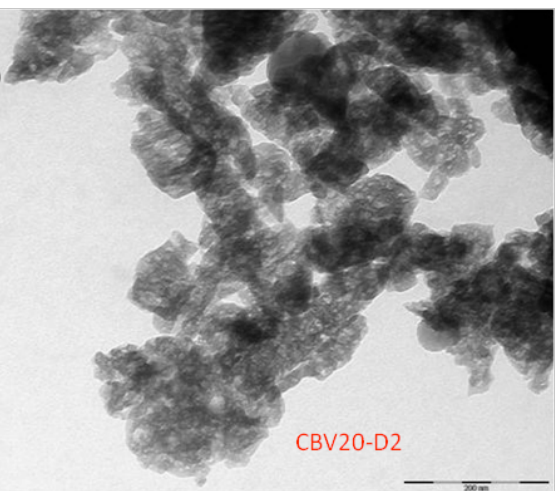

Figure 3. TEM microphotographs of CBV20 Mordenite. (a) CBV20: parent sample. (b) CBV20-D1: alkaline treated sample with $0.2 \mathrm{M} \mathrm{NaOH}$, at $353 \mathrm{~K}$. (c) CBV20-D2: alkaline treated sample with $1 \mathrm{M} \mathrm{NaOH}$, at $353 \mathrm{~K}$.

The formation of mesoporosity during the alkaline treatments was further proved by means of $\mathrm{N}_{2}$ adsorption studies. The evolution of mesoporosity by increasing severity of the alkaline treatment was clearly supported by the steady increase of the mesoporous volume given in Table 4, but was even more evident upon inspection of the adsorption isotherms of $\mathrm{N}_{2}$ (Figure 4), where it is obvious that the $\mathrm{N}_{2}$ uptake at high $\mathrm{P} / \mathrm{P}_{0}$ increased with the concentration of $\mathrm{NaOH}$ used during treatment. This increase was accompanied by a less pronounced diminution of the micropore volume, as it was suggested by the $25 \%$ loss of crystallinity, observed by means of X-Ray diffraction and corroborated from the micropore volume values reported in Table 4. 

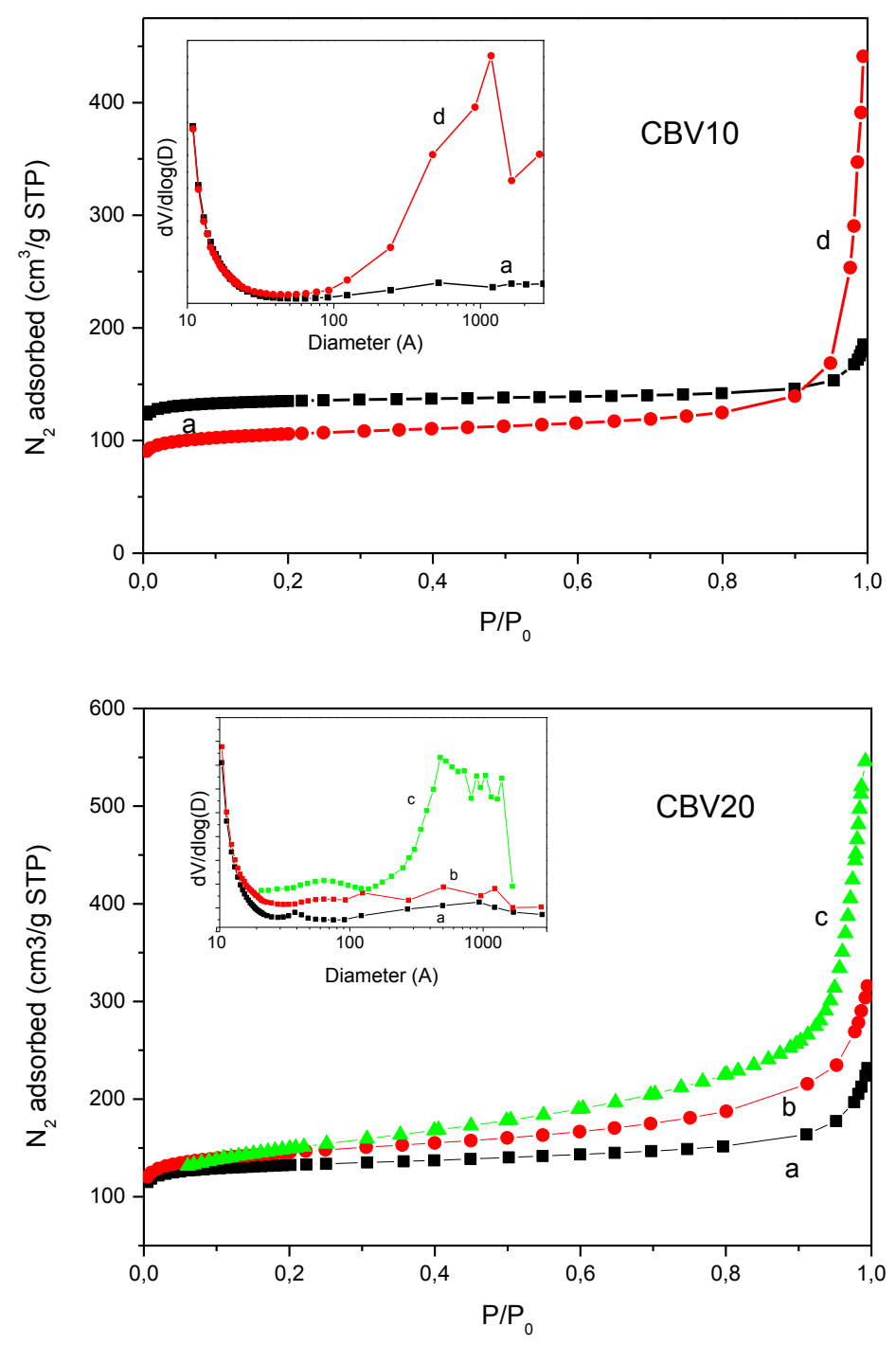

Figure 4. Adsorption isotherms of $\mathrm{N}_{2}$ of the original and alkaline treated Mordenites.

(a) parent MOR, (b) D1 treatment, (c) D2 treatment, (d) D3 treatment. Insets of the figures show the corresponding BJH pore distributions.

Thus, it can be concluded that it is possible to generate mesoporosity on Mordenites with different $\mathrm{Si} / \mathrm{Al}$ ratios by controlling the severity of the alkaline treatment. This treatment is accompanied by a selective extraction of $\mathrm{Si}$, resulting in Mordenite zeolites with lower $\mathrm{Si} / \mathrm{Al}$ ratios and more developed mesoporosity than the parent zeolites, with simultaneous minor modification of the microporosity. However, there is a limit on this treatment since very large 
mesoporosity and, therefore, very low $\mathrm{Si} / \mathrm{Al}$ ratio have a negative effect on the thermal stability of the resulting material. In addition, the $\mathrm{Si} / \mathrm{Al}$ ratio of the parent Mordenite has a strong influence on the efficiency of extracting Si by alkaline treatments. It was observed that the mesoporosity formation on the Mordenite sample having a $\mathrm{Si} / \mathrm{Al}$ ratio of 6.5 was much lower than that on the Si rich material ( $\mathrm{Si} / \mathrm{Al}$ ratio of 10). In fact, it is known that zeolites of high Al content are less sensitive to alkaline treatments [13]. Thus, it is expected that sample CBV20-D1 with an optimal combination of micropore, mesopore volume and acidity will perform much better than the parent zeolite during catalytic processes involving bulcky molecules, which preferentially react on the acid sites of the external surface. Both pyrolysis of biomass or catalytic cracking of gasoil are such processes.

\subsection{Physicochemical characteristics of zeolitic catalysts after acid treatments}

As stated above, the $\mathrm{Si} / \mathrm{Al}$ ratio of the desilicated mordenite materials decreases with the alkaline treatment. This could have a negative effect on the stability and acid strength of the final catalyst. Thus, we have conducted a new series of dealumination experiments on one desilicated mordenite (CBV20-D1) through acid treatments using $\mathrm{HNO}_{3}$ aqueous solutions of different concentrations and at different temperatures (see Table 2 for experimental details). For comparison purposes, acid treatment of the parent CBV-20 zeolite was performed as well. Table 6 shows the chemical composition and textural properties of acid treated samples in comparison to the parent materials.

Table 6. Textural properties and chemical compositions of the parent and acid -treated Mordenite samples.

$\begin{array}{lccccc}\text { Catalyst } & \begin{array}{c}\text { Molar } \\ (\mathrm{Si} / \mathrm{Al})^{\mathrm{a}}\end{array} & \begin{array}{c}\mathrm{V}_{\text {MICRO }}{ }^{\mathrm{b}} \\ (\mathrm{cc} / \mathrm{g})\end{array} & \begin{array}{c}\mathrm{V}_{\text {MESO }}{ }^{\mathrm{c}} \\ (\mathrm{cc} / \mathrm{g})\end{array} & \begin{array}{c}\text { BET } \\ \text { Surface Area } \\ \left(\mathrm{m}^{2} / \mathrm{g}\right)\end{array} & \begin{array}{c}\text { Langmuir } \\ \text { Surface Area } \\ \left(\mathrm{m}^{2} / \mathrm{g}\right)\end{array} \\ \text { CBV20 } & 10.0 & 0.182 & 0.10 & 433 & 583 \\ \text { CBV20-A2 } & 16.5 & 0.170 & 0.073 & 433 & 599 \\ \text { CBV20-D1 } & 8.1 & 0.180 & 0.195 & 481 & 646 \\ \text { CBV20-D1-A1 } & 8.6 & 0.155 & 0.142 & 458 & 619 \\ \text { CBV20-D1-A2 } & 22.2 & 0.160 & 0.192 & 438 & 588 \\ \text { CBV20-D1-A3 } & 75.0 & 0.106 & 0.140 & 361 & 501 \\ { }^{\text {a }} \text { ICP analyses; }{ }^{b} \text { t-plot method; }{ }^{c} \text { BJH-KJS Adsorption pore volume between } 1.7 \text { and } 30 \mathrm{~nm} .\end{array}$


The X-Ray diffraction patterns shown in Figure 5 clearly indicate that crystallinity of Mordenite samples was partially retained. This was further supported by the micropore volume values given in Table 6 , which shows that minor diminution of the micropore volume occurred upon acid treatments with respect to the parent zeolites. The retention of crystallinity was achieved without affecting the porosity of the parent Mordenites. This was clearly seen in the TEM images (Figure 6), where no modification of the mesoporous structure of the mordenite was observed. In addition, it was further supported by the fact that the mesoporosity of the acid treated materials did not change significantly upon $\mathrm{HNO}_{3}$ washing.

The $\mathrm{Si} / \mathrm{Al}$ ratios of acid treated samples increased as the temperature or the acid concentration of the treatment increased, resulting in high silica mesoporous Mordenite samples. Even more important than porosity, were the dramatic changes in acidity observed in the acid-submitted mordenites. Indeed, alkaline treated materials had a lower acidity than the parent mordenites as it is shown in Table 5 and the acid site concentration and strength of acid sites diminished with increasing severity of the alkaline treatment, even though the $\mathrm{Al}$ concentration in those samples increased. On the other hand, when desilicated mordenites were acid treated under mild conditions, the number of the Brönsted acid sites increased (sample CBV20-D1-A1). CBV20-D1-A1 had approximately the same Al content as the alkaline treated-parent zeolite, but its Brönsted acid concentration was nearly 1.5 times higher, as shown in Table 7. This is extremely important regarding the final catalytic activity of the hierarchical porous mordenite developed in this work.

Table 7. Acidity of parent zeolites and optimal desilicated zeolites.

\begin{tabular}{|c|c|c|c|c|c|c|c|}
\hline \multirow{2}{*}{ Samples } & \multirow{2}{*}{$\mathrm{Si} / \mathrm{Al}$} & \multicolumn{3}{|c|}{$\begin{array}{l}\text { Brönsted Acidity } \\
(\mathrm{mmoles} \text { Py/g })^{\mathrm{a}}\end{array}$} & \multicolumn{3}{|c|}{$\begin{array}{l}\text { Lewis Acidity } \\
(\mathrm{mmoles} \mathrm{Py} / \mathrm{g})^{\mathrm{a}}\end{array}$} \\
\hline & & $523 \mathrm{~K}$ & $623 \mathrm{~K}$ & $673 \mathrm{~K}$ & $523 \mathrm{~K}$ & $623 \mathrm{~K}$ & $673 \mathrm{~K}$ \\
\hline CBV20 & 10.0 & 0.477 & 0.389 & 0.262 & 0.080 & 0.080 & 0.073 \\
\hline CBV20-A2 & 16.5 & 0.287 & 0.176 & 0.10 & 0.050 & 0.050 & 0.046 \\
\hline CBV20-D1 & 8.1 & 0.264 & 0.165 & 0.155 & 0.060 & 0.055 & 0.047 \\
\hline CBV20-D1-A1 & 8.6 & 0.390 & 0.236 & 0.142 & 0.042 & 0.037 & 0.037 \\
\hline CBV20-D1-A2 & 22.2 & 0.278 & 0.198 & 0.095 & 0.050 & 0.043 & 0.035 \\
\hline CBV20-D1-A3 & 75.0 & 0.044 & 0.014 & 0.009 & 0.008 & 0.008 & 0.007 \\
\hline
\end{tabular}


Further increase of the acid treatment severity caused a strong dealumination of the parent desilicated mordenite, leading to high silica mordenites with $\mathrm{Si} / \mathrm{Al}$ ratios as higher as 75. Naturally, the acid site concentration in these samples diminished as the $\mathrm{Si} / \mathrm{Al}$ ratio increased. It can be concluded that fine tuning of the porous and acid properties of the final mordenite zeolite is possible by subsequent desilication-dealumination treatments on the parent material, while the meso and microporosity can be finelly tuned by controlling the severity of the first alkaline treatment. Thus, the most appropriate texture and acidity on MOR catalysts can be selected for each target process.

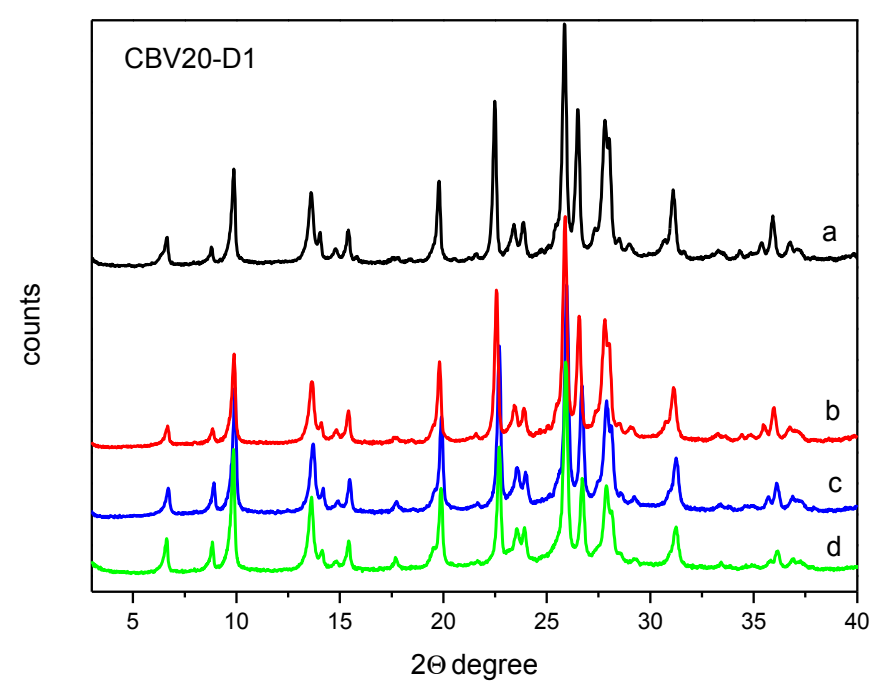

Figure 5. X-Ray Diffraction patterns of CBV20, alkaline treated and dealuminated-desilicated samples. (a) CBV20-D1, (b) CBV20-D1-A1, (c) CBV20-D1-A2 and (d) CBV20-D1-A3. 

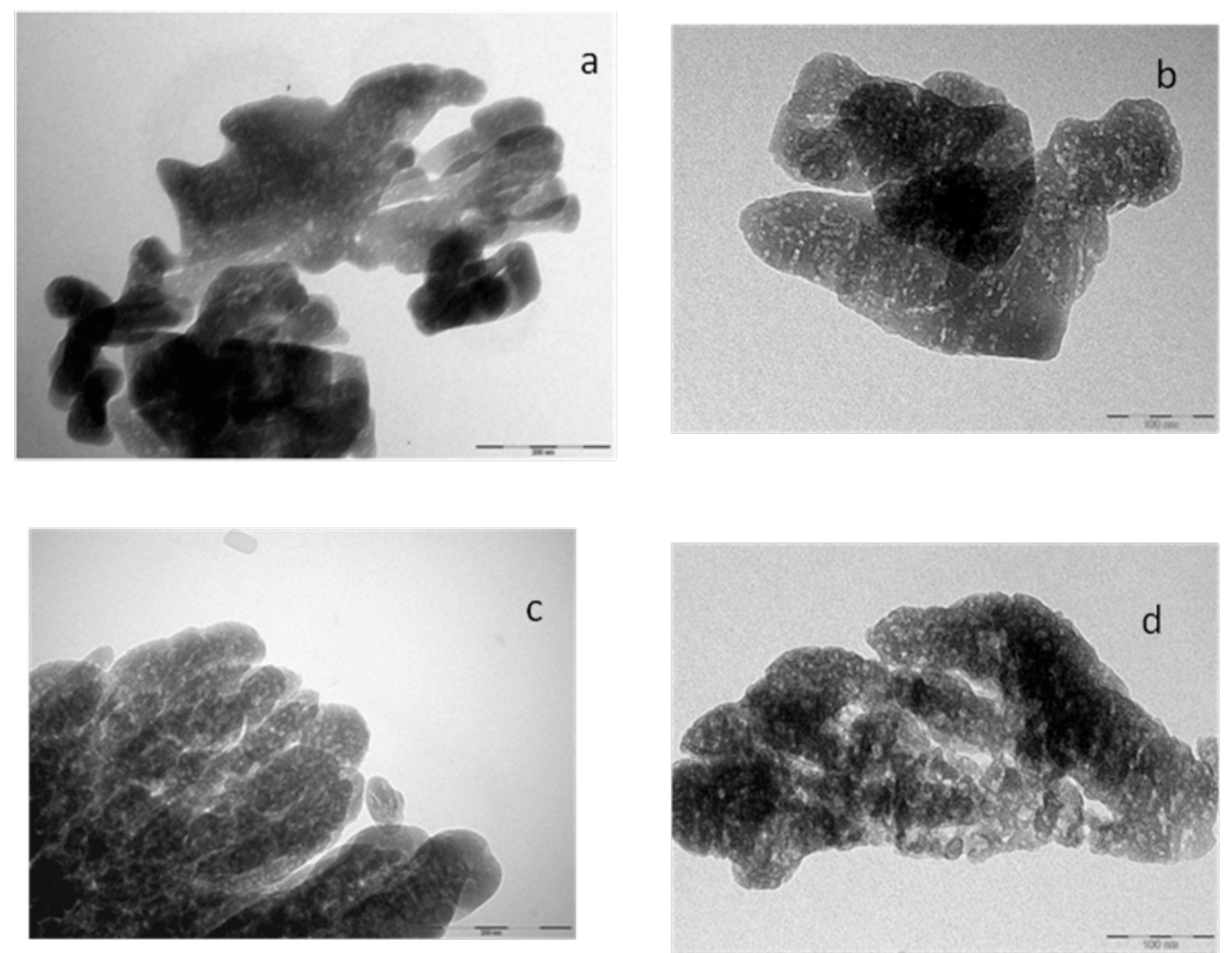

Figure 6. TEM microphotographs of CBV20 alkaline treated and dealuminated-desilicated samples. (a) CBV20-D1, (b) CBV20-D1-A1, (c) CBV20-D1-A2 and (d) CBV20-D1-A3.

\subsection{Non-catalytic and catalytic flash pyrolysis of biomass feedstock}

The product yields (wt. \% based on biomass) from the non- catalytic and the catalytic using the untreated zeolites pyrolysis of the lignocellulosic biomass (beech wood) are shown in Table 8. The most representative organic compounds of the thermal bio-oil were classified in 14 major functional groups; aromatic hydrocarbons (AR), aliphatic hydrocarbons (ALI), phenols (PH), furans (FUR), acids (AC), esters (EST), alcohols (AL), ethers (ETH), aldehydes (ALD), ketones (KET), polyaromatic hydrocarbons (PAH), sugars (SUG) and heavier compounds (HV). Among them, aromatic hydrocarbons, aliphatic hydrocarbons and alcohols were considered desirable products for biofuels production, while phenols and furans were also regarded as high added value chemicals. On the other hand, acids are responsible for the corrosiveness of the bio-oil and were thus considered undesirable. The same stands for ketones and aldehydes, which are related with the instability of the bio-oil during transport and storage. Ethers, esters and oxygenates in general are also undesirable as they reduce the heating value of the bio-oil. Finally, PAHs and nitrogen compounds are detrimental for 
environmental reasons. The same classification in bio-oil composition was also used in the catalytic experiments.

Table 8. Product yields (wt. \% on biomass) from the non-catalytic and catalytic pyrolysis of lignocellulosic biomass (untreated zeolites used as candidate catalysts)

\begin{tabular}{lcccccc}
\hline Catalyst & $\begin{array}{c}\text { Total liquids } \\
\text { (Bio-oil) }\end{array}$ & $\begin{array}{c}\text { Organics } \\
\text { (in bio- } \\
\text { oil) }\end{array}$ & $\begin{array}{c}\text { Water } \\
\text { (in bio-oil) }\end{array}$ & Gases & $\begin{array}{c}\text { Char }+ \\
\text { coke on } \\
\text { catalyst }\end{array}$ & Oxygen ${ }^{\text {(a) }}$ \\
\hline $\begin{array}{l}\text { Non-catalytic } \\
\text { (silica sand) }\end{array}$ & 59.04 & 37.46 & 21.58 & 17.76 & 23.20 & 40.10 \\
CBV10 & 46.47 & 17.91 & 28.56 & 23.11 & 30.39 & 28.57 \\
CBV20 & 43.33 & 14.37 & 28.96 & 26.10 & 30.61 & 31.20 \\
\hline \multicolumn{1}{l}{ (a) $w$ wt. \% on organics in bio-oil }
\end{tabular}

It is obvious from Table 8 that both mordenite catalysts resulted in a pronounced decrease in total liquid yield, compared with the non catalytic pyrolysis (use of inert silica sand) and a simultaneous increase in water content in the bio-oil, gaseous products and solid yields (coke production), at the expense of the organic fraction yield. The bio-oil production was severely reduced, leading to significantly low organic yields. These effects were attributed to the strong zeolitic acidity, especially of the Brönsted type, in agreement with the relevant literature $[3,33,34]$. Increased water yield is related with enhanced dehydration reactions, while lower organic yield and higher gases are related with enhanced cracking reactions, as additionally supported by increased ethylene and propylene yields. Very interesting is the enhancement of CO (decarbonylation reactions) production when using these two catalysts (Table 9).

Table 9. Gas product yields (wt. \% on biomass) from non-catalytic and catalytic pyrolysis of lignocellulosic biomass (untreated zeolites used as candidate catalysts)

\begin{tabular}{lccccccccc}
\hline Catalyst & $\mathbf{H}_{\mathbf{2}}$ & $\mathbf{C O}$ & $\mathbf{C O}_{\mathbf{2}}$ & $\mathbf{C H}$ & $\mathbf{C}_{\mathbf{2}}$ & $\mathbf{C}_{\mathbf{2}}=$ & $\mathbf{C}_{\mathbf{3}}$ & $\mathbf{C}_{\mathbf{3}}=$ & $\mathbf{C}_{\mathbf{4}}-\mathbf{C}_{\mathbf{6}}$ \\
\hline $\begin{array}{l}\text { Non-catalytic } \\
\text { (silica sand) }\end{array}$ & 0.04 & 6.51 & 9.52 & 0.90 & 0.15 & 0.20 & 0.04 & 0.12 & 0.28 \\
CBV10 & 0.07 & 9.60 & 10.37 & 1.18 & 0.22 & 0.75 & 0.15 & 0.32 & 0.47 \\
CBV20 & 0.05 & 11.86 & 10.49 & 1.43 & 0.21 & 1.07 & 0.20 & 0.43 & 0.36 \\
\hline
\end{tabular}

Between the two materials, CBV20 was more active as it produced more pyrolysis gases (mainly CO and light hydrocarbons) and induced a more pronounced decrease in the organic 
liquid yield than CBV10. The higher activity of the CBV20 mordenite was attributed to its higher Brönsted and Lewis acidity (see Table 5). The decrease in the oxygen content of the bio-oil, which is a crucial improvement for its utilization as a fuel substitute, was significant for both materials. The CBV10 however, seemed to be more promising since it yielded more organic liquid products with slightly less oxygen content than CBV20.

The composition of the bio-oil (wt. \% on total organics) produced from the non-catalytic and catalytic flash pyrolysis of lignocellulosic biomass is shown in Figure 7. The main groups identified in the organic phase of catalytically produced bio-oils, as can be seen in Figure 7, were phenols, aromatics and PAHs. On the contrary acids, esters, furans, ethers, aldehydes and ketones were also present but, in most cases, in lower relative abundance (chromatogram peak area \%) as compared to the non-catalytic experiments. Undesirable products such as acids, ketones and heavier compounds were reduced with both catalysts. The more acidic CBV20 exhibited slightly higher selectivity towards aromatic hydrocarbons and achieved higher conversion of acids and ketones than the less acidic CBV10.

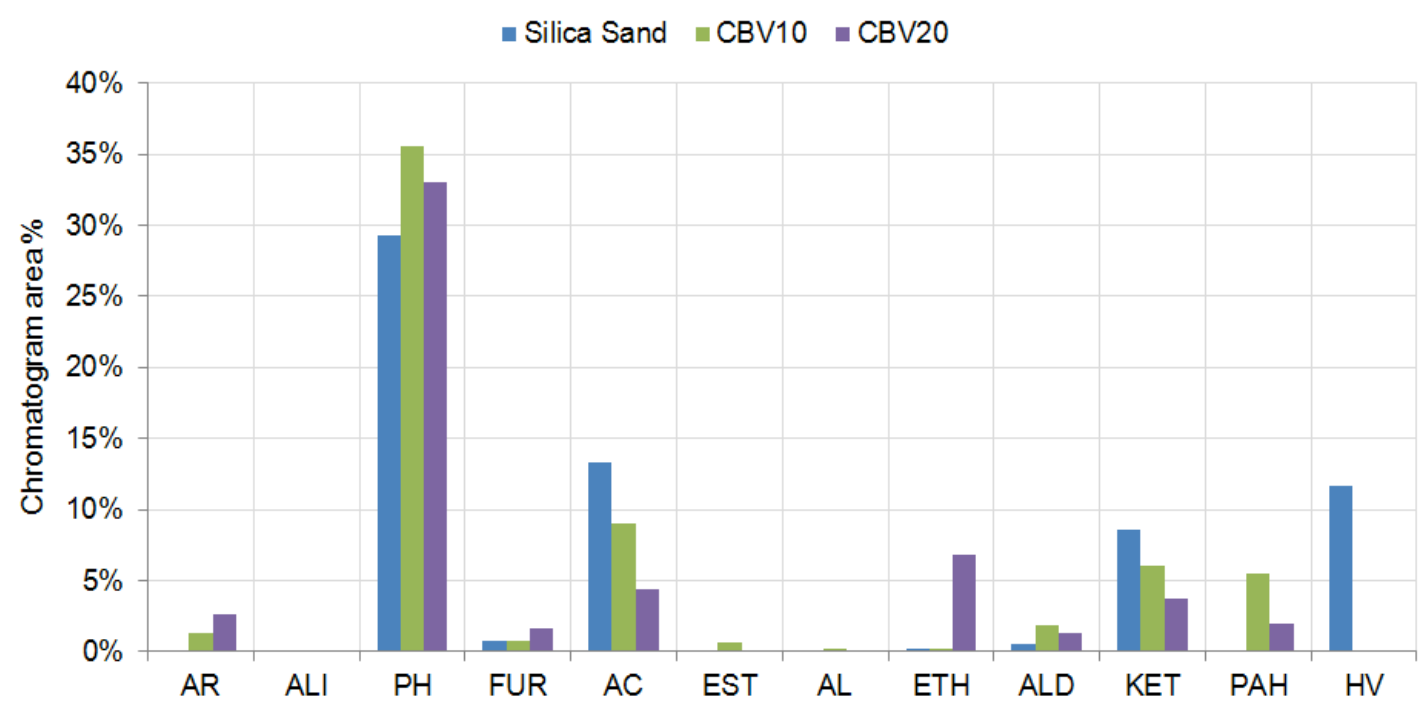

Figure 7. Main product distribution of the liquid phase bio-oil obtained by thermal (use of silica sand) or catalytic pyrolysis on parent MOR Zeolites.

In an effort to enhance mass transfer effects in order to limit secondary reactions, probably responsible for the low organic yields, and enhance accessibility of the larger molecules to the catalyst, the zeolites were submitted to alkaline treatments, as previously described, aiming to form mesoporosity in the samples. The effect of alkaline treatment on product yields is summarised in Table 10 . 
Table 10. Effect of alkaline treatment on product yields (wt.\% on biomass)

\begin{tabular}{lcccccc}
\hline Catalyst & $\begin{array}{c}\text { Total } \\
\text { liquids } \\
\text { (Bio-oil) }\end{array}$ & $\begin{array}{c}\text { Organics } \\
\text { (in bio- } \\
\text { oil) }\end{array}$ & $\begin{array}{c}\text { Water } \\
\text { (in bio-oil) }\end{array}$ & Gases & $\begin{array}{c}\text { Char }+ \\
\text { coke on } \\
\text { catalyst }\end{array}$ & Oxygen $^{(\mathbf{a})}$ \\
\hline $\begin{array}{l}\text { Non-catalytic } \\
\text { (silica sand) }\end{array}$ & 59.04 & 37.46 & 21.58 & 17.76 & 23.20 & 40.10 \\
CBV10 & 46.47 & 17.91 & 28.56 & 23.11 & 30.39 & 28.57 \\
CBV10-D3 & 49.34 & 21.48 & 27.86 & 23.33 & 27.29 & 31.24 \\
CBV20 & 43.33 & 14.37 & 28.96 & 26.10 & 30.61 & 31.20 \\
CBV20-D1 & 43.19 & 10.97 & 32.23 & 27.58 & 29.23 & 21.81 \\
\hline \multicolumn{2}{r}{ (a) wt.\% on organics in bio-oil } & & & & &
\end{tabular}

Starting from the CBV10 material, it was evident that alkaline treatment (CBV10-D3 sample) modified its catalytic performance. The reduction in the surface area and acidity of the catalyst (see Tables 4 and 5) resulted in reduction of the catalytic activity. Total liquids and organic phase were slightly enhanced at the expense of water formation, while the oxygen content of the organic fraction slightly increased. However, taking into consideration the severe reduction in the acidity and surface area of the catalysts, the increase in the oxygen at the organic fraction was not as high as it would have been expected. The mesoporosity created after the alkaline treatment tentatively had a beneficial effect in the catalytic deoxygenation performance.

An opposite effect was however observed with the CBV20 sample after the alkaline treatment. The retention of the high surface area of sample CBV20-D1, combined with the formation of mesopores, resulted in enhanced activity despite the reduction in its acidity. The treated sample led to lower organic and higher water yields, with a consistent increase in gases (mainly $\mathrm{CO}_{2}$ ) and water. It is worth noting that despite the increased activity of the catalyst, coke formation was lower than in the parent material. The enhanced decarboxylation and dehydration reactions, combined with suppressed carbon deposition on the catalyst, resulted in a remarkable decrease in the oxygen content of the organic fraction and therefore, in liquid bio-oil product of superior quality.

The composition of the produced pyrolysis gases is given in Table 11, where slight variations are observed as a result of the alkaline treatment. In the case of the CBV10 sample, an inhibition of secondary cracking reactions due to its reduced activity could account for the increase in total liquids and organic yield, a fact supported by the small decrease in $\mathrm{C}_{2}$ and $\mathrm{C}_{3}$ hydrocarbons present in the pyrolysis gases, while decarbonylation reactions seemed rather unaffected. The same trend was observed in the case of the CBV20 sample, where alkaline 
treatment still had no effect on decarbonylation reactions, however decarboxylation and cracking were enhanced, as indicated from the increase in $\mathrm{CO}_{2}$ and all light hydrocarbons. This fact could be explained considering the retention of the material's high surface area and the presence of mesopores, able to process the larger molecules of the pyrolysis vapours.

Table 11. Effect of alkaline treatment on composition of gases (wt.\% on biomass)

\begin{tabular}{lccccccccc}
\hline Catalyst & $\mathbf{H}_{\mathbf{2}}$ & $\mathbf{C O}$ & $\mathbf{C O}_{\mathbf{2}}$ & $\mathbf{C H}_{\mathbf{4}}$ & $\mathbf{C}_{\mathbf{2}}$ & $\mathbf{C}_{\mathbf{2}}=$ & $\mathbf{C}_{\mathbf{3}}$ & $\mathbf{C}_{\mathbf{3}}=$ & $\mathbf{C}_{\mathbf{2}}-\mathbf{C}_{\mathbf{6}}$ \\
\hline $\begin{array}{l}\text { Non-catalytic } \\
\text { (silica sand) }\end{array}$ & 0.04 & 6.05 & 9.27 & 0.78 & 0.14 & 0.17 & 0.04 & 0.12 & 0.16 \\
CBV10 & 0.07 & 9.60 & 10.37 & 1.18 & 0.22 & 0.75 & 0.15 & 0.32 & 0.47 \\
CBV10-D3 & 0.03 & 9.42 & 10.81 & 1.18 & 0.20 & 0.66 & 0.06 & 0.30 & 0.66 \\
CBV20 & 0.05 & 11.86 & 10.49 & 1.43 & 0.21 & 1.07 & 0.20 & 0.43 & 0.36 \\
CBV20-D1 & 0.06 & 11.85 & 11.35 & 1.51 & 0.28 & 1.06 & 0.26 & 0.53 & 0.66 \\
\hline
\end{tabular}

With regard to the effect of alkaline treatment on the composition of the organic liquid phase, the porosity and acidity of the candidate catalytic samples also seemed to play an important role. The alkaline treatment of the CBV10 retained all undesirable components at the same low or even lower levels (acids, ketones) and it significantly increased the phenols, leading to a bio-oil consisting mainly of phenols. The decreased acidity and overall activity of the treated catalyst resulted in lower selectivity towards hydrocarbons (aromatic hydrocarbons and PAHs) and higher heavy compounds yield, as compared with the parent material.

In the case of the CBV20, alkaline treatment had a different effect. On one hand, it retained most undesirable components (acids and ketones) at low levels but at the same time reduced phenol formation. Formation of PAHs was remarkably increased, possibly due to the increased consumption of the in-situ generated hydrogen by the dehydration reactions (which resulted in high hydrogen deficiency and caused formation of PAHs instead of aromatic hydrocarbons) and the presence of mesopores that allowed the formation of larger molecules.

A very important property of the targeted high quality bio-oil is its oxygen content. It is thus considered important to develop a catalyst that has the ability to retain a high yield of organic liquid product, while affecting its composition in such a way, that it reduces its oxygen content. Figure 10 summarizes the performance of each catalyst (fresh and treated) in the bio-oil produced during biomass pyrolysis by presenting quantity vs. quality (oxygen content) effects on the bio-oil produced. 


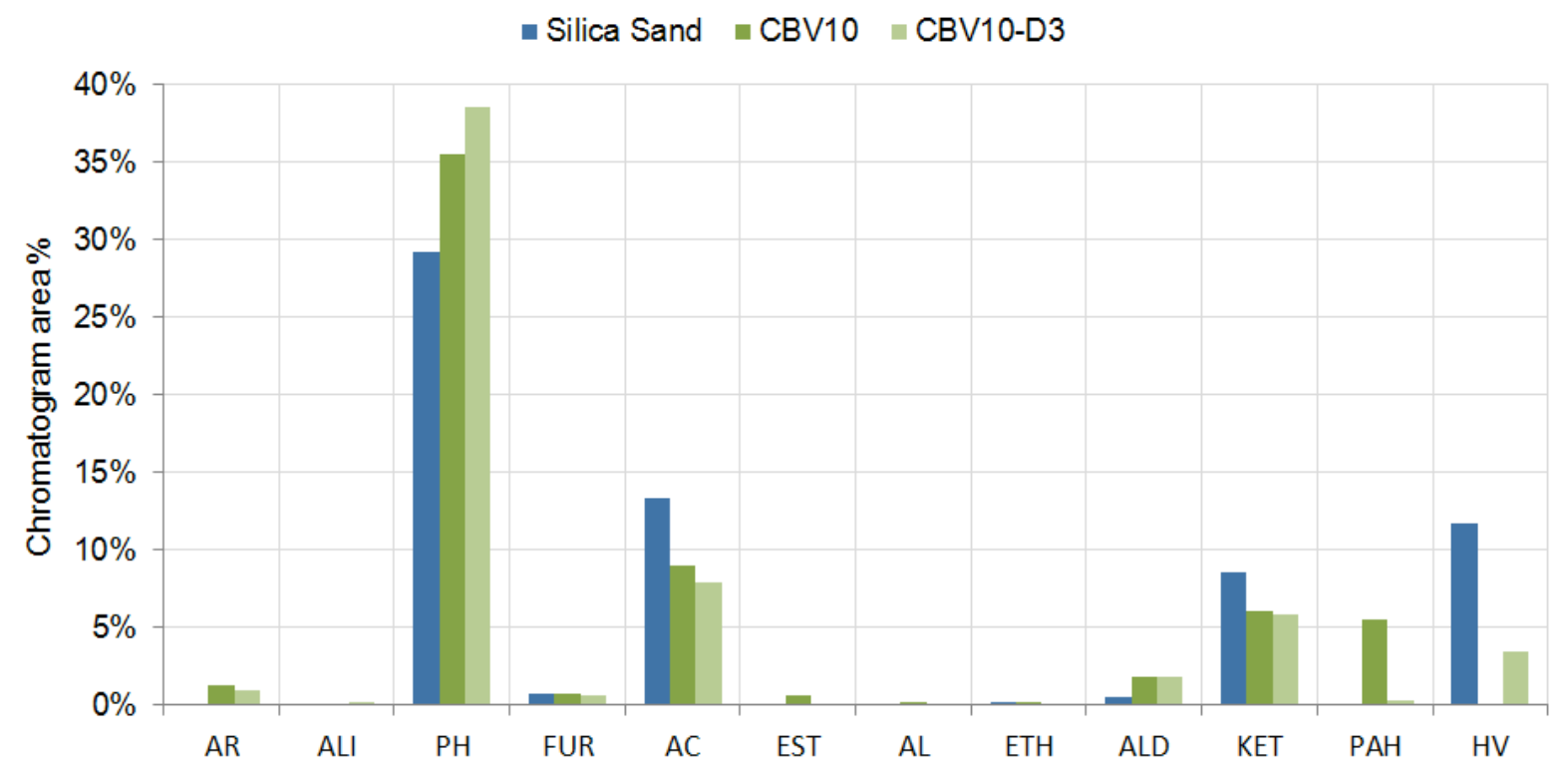

Figure 8. Main product distribution of the liquid phase bio-oil obtained by catalytic pyrolysis on silica sand and alkaline treated (CBV10-D3) and parent high-Al content (CBV10) MOR Zeolites .

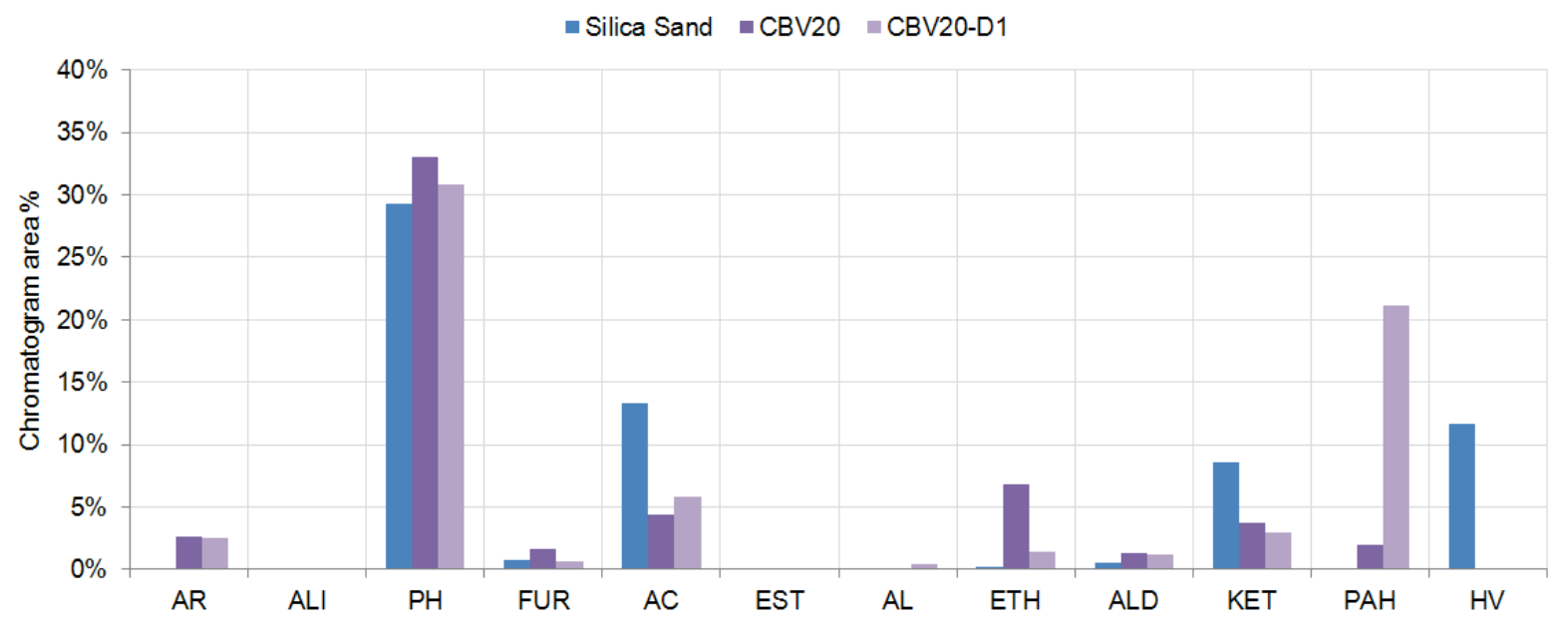

Figure 9. Main product distribution of the liquid phase bio-oil obtained by catalytic pyrolysis on silica sand and alkaline treated (CBV20-D3) and parent low-Al content (CBV-20) MOR zeolites. .

It is considered more clear if instead of the oxygen content, catalyst are compared based on the $\mathrm{C} / \mathrm{O}$ content in the organic fraction they produce, additionally marking the possible upper and lower limits during the biomass pyrolysis process. Taking into account that $\mathrm{C} / \mathrm{O}$ ratio of biomass is around 1 , lower limit is the $\mathrm{C} / \mathrm{O}$ content of the biomass itself, and upper limit is the $\mathrm{C} / \mathrm{O}$ content of the product if all the oxygen could be converted to $\mathrm{CO}_{2}$ and $\mathrm{H}_{2} \mathrm{O}$. 
As it can be seen in Figure 10, a particularly beneficial effect was observed in the case of the CBV20 catalyst, where treatment caused a small decrease of organic yield, but a pronounced increase of the carbon/oxygen ratio, thus leading to a much higher quality bio-oil. In the case of the CBV10 catalyst, the alkaline treatment resulted in an increase in the organic fraction yield, which was accompanied however by a decrease of the carbon/oxygen ration.

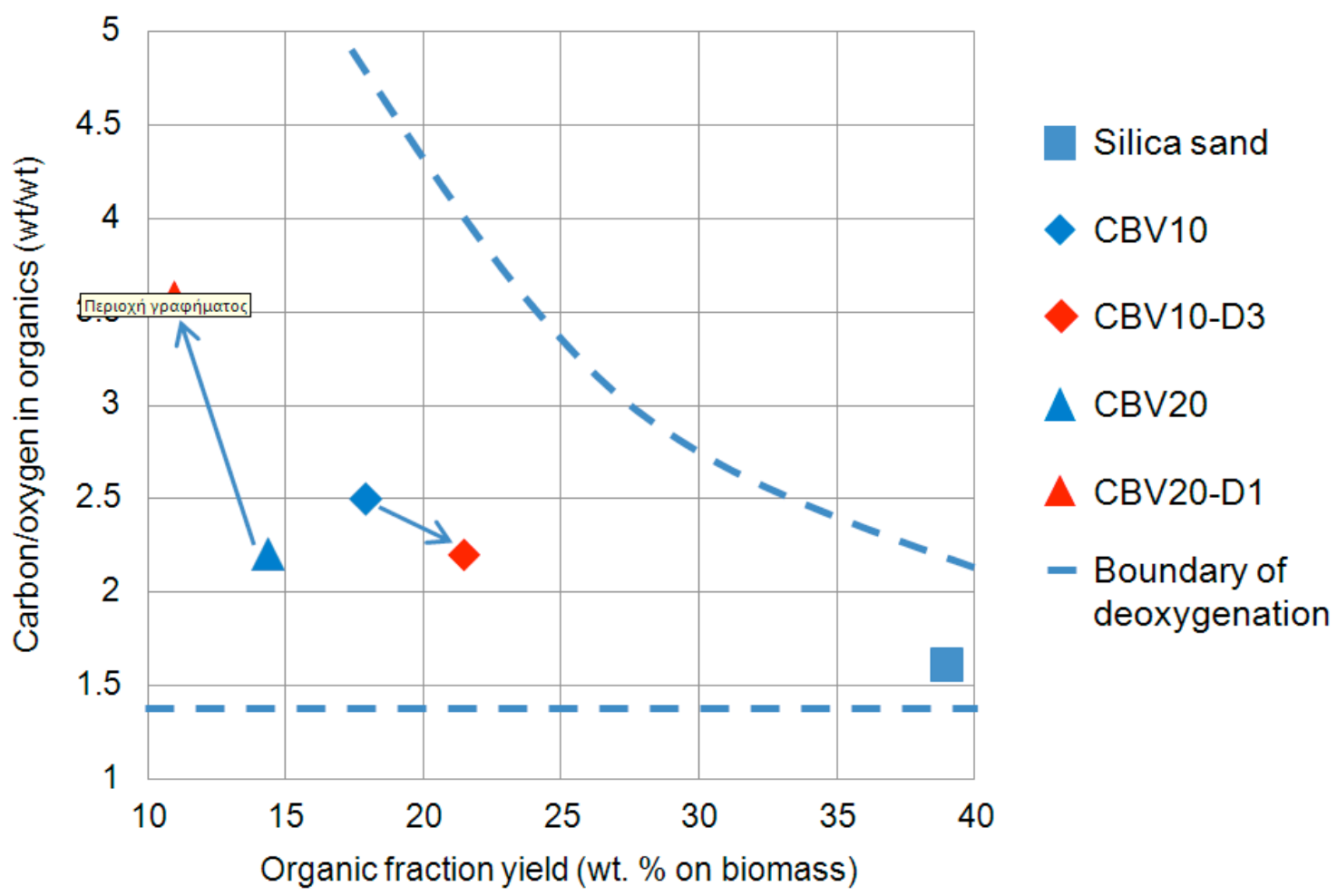

Figure 10. Effect of alkaline treatment on mordenites for the deoxygenation performance in the catalytic pyrolysis of biomass. Arrows show the course of the alkaline treatment.

\subsection{Catalytic cracking of gasoil}

Although biomass pyrolysis is a promising technology to produce fuels, the current technology for obtaining carburant is still the catalytic cracking of vacuum gasoil. Thus, it may be worth to test the mordenite-based catalysts for this process. It was shown above that the total acidity of the modified mordenites studied in this work decreased due to alkaline treatment (see Table 5), while high acidity is necessary for the catalytic cracking of vacuum gasoil. Moreover, the $\mathrm{Si} / \mathrm{Al}$ ratio of the desilicated Mordenite materials decreased. This could be due to generation of extra-framework aluminum during the alkaline treatment, which would have a negative effect in the catalytic cracking of vacuum gasoil. In order to remove the extra-framework aluminum, a second treatment using $\mathrm{HNO}_{3}$ was carried out (see 2.1.2.) generating mesopore-modified mordenite samples with higher total acidity. The cracking of 
vacuum gasoil was studied over the newly treated samples (desilicated and then dealuminated). The higher activity and external surface area mordenite was selected for the tests, along with the parent sample for comparison purposes (CBV20, CBV20-D1 and CBV20-D1A1).

The results obtained in the catalytic cracking of vacuum gasoil are shown in Figures 1113. An increase in the total conversion for the desilicated and dealuminated sample (CBV20D1A1) was observed. By fitting conversion results to a second order kinetics, the rate constants found were: $0.0125,0.0124$ and $0.0155 \mathrm{~g}_{\text {oil }} \mathrm{h}^{-1} \mathrm{~g}_{\text {zeolite }}$ for CBV20, CBV20-D1 and CBV20-D1A1respectively. The detrimental effect of extra-framework aluminum in the catalytic cracking activity is well known because, if cationic, it poisons acid centres decreasing the overall acidity. Thus, the best results were obtained with the CBV20-D1A1 sample, in which an important part of the extra-framework aluminum was removed and the original acidity of the parent MOR zeolite was recovered (Table 7). The CBV20-D1 did not improve the total conversion due to its lower acidity that was not compensated by its improved external surface.

When looking at the product selectivities calculated at constant conversion values, it can be seen that the desilication treatment enhanced the yield of middle distillates, especially light cycle oil (LCO), along with a minor improvement in the gasoline yield, and a correspondent decrease in the production of $\mathrm{C} 1-\mathrm{C} 4$ gases. This product distribution indicates that the increase in the external surface, while preserving the acidity enhances diffusion of vacuum gasoil, and therefore selectivity was shifted to primary middle distillates and reduced for the secondary gases production. The decrease in the yield of gases was compensated by an improvement in their quality, with a higher olefinicity of the $\mathrm{C}_{3}$ and $\mathrm{C}_{4}$ fraction (Figure 12).

Moreover, the influence of the external surface area was very clear in bottoms conversion (Figure 13). In fact, the selectivity to bottoms was very low for the sample CBV20-D1A1 sample (similar to what would be expected from a USY zeolite) and much lower than that observed on the parent and alkaline-treated MOR zeolites. This observation is probably related with a more accessible and active surface that was able to crack the heaviest part of the vacuum gasoil as well as to the high acid site concentration attained on the sample CBV20D1A1. In summary, considering cracking of gasoil, desilicated and especially desilicated and dealuminated mordenites exhibited the highest activity and selectivity towards LCO with the best olefinicity in gases and higher bottoms conversion. Therefore, an optimized desilicateddealuminated mordenite additive could be an interesting candidate as component of the FCC catalyst for high LCO yield. 
TOTAL CONVERSION WT\%
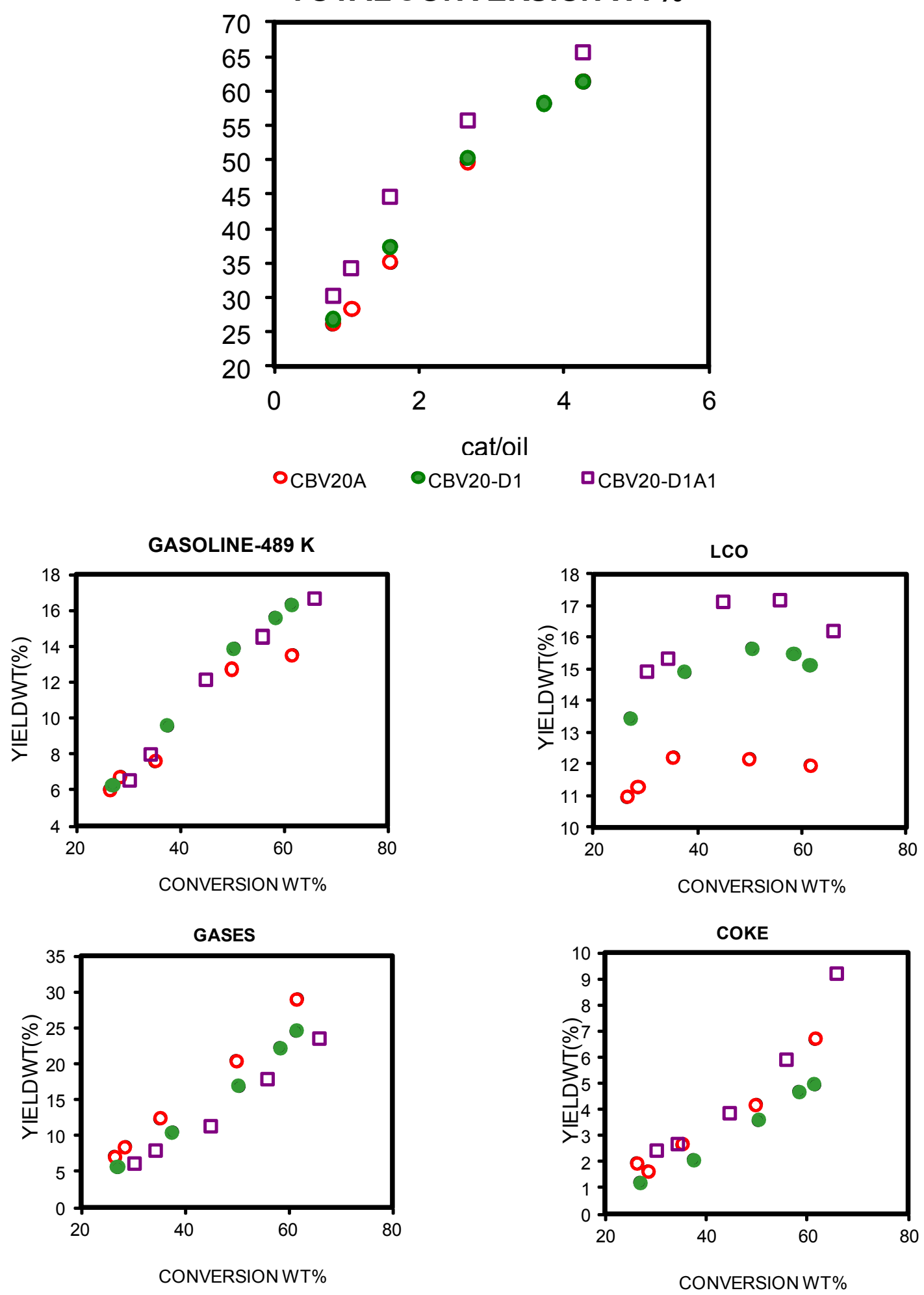

Figure 11. Total conversion and selectivities in the catalytic cracking of vacuum gasoil at 793 $\mathrm{K} . \mathrm{TOS}=30 \mathrm{~s}$ on mesoporous-modified mordenites. 


\section{OLEFINS C3C4 / PARAFFINS C3-C4}

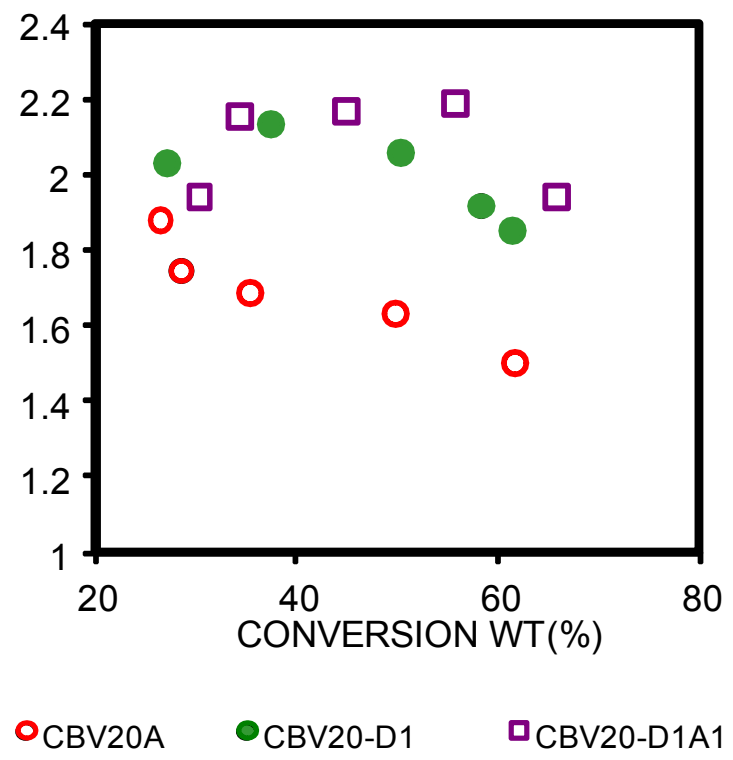

Figure 12. C3-C4 olefin to paraffin ratio in the catalytic cracking of vacuum gasoil at $793 \mathrm{~K}$. TOS $=30 \mathrm{~s}$ on mesoporous-modified mordenites.

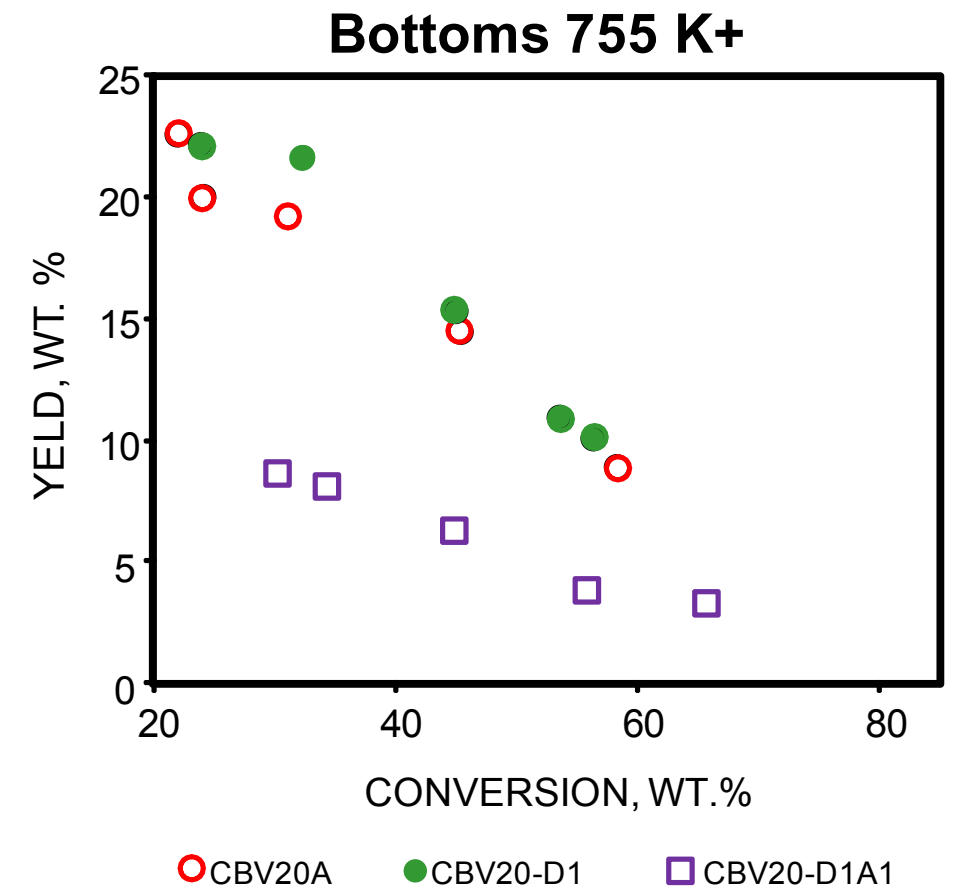


Figure 13. Bottoms $\left(482^{\circ} \mathrm{C}+\right)$ selectivity in the catalytic cracking of vacuum gasoil at $793 \mathrm{~K}$. $\mathrm{TOS}=30 \mathrm{~s}$ on mesoporous-modified mordenites.

\section{Conclusions}

The generation of mesoporosity in zeolites can enhance the accessibility of large biomass derived molecules and thus the catalytic activity, possibly limited by the narrow entrance of micropores. Two commercial Mordenites were subjected to an alkaline solution treatment to create mesoporosity. Characterization of the samples evidenced that it is possible to generate mesoporosity on Mordenites with different $\mathrm{Si} / \mathrm{Al}$ ratios by controlling the severity of the alkaline treatment. This treatment is accompanied by a selective extraction of $\mathrm{Si}$, resulting in Mordenite zeolites with low $\mathrm{Si} / \mathrm{Al}$ ratio and with both micro- and meso- pores. When tested in biomass pyrolysis parent mordenites achieved a significant decrease in the oxygen content of the bio-oil produced, which is a crucial improvement for its utilization as a fuel substitute. However, the low $\mathrm{Si} / \mathrm{Al}$ ratio seemed to be more promising, since it yielded more organic liquid products with slightly less oxygen content than the high $\mathrm{Si} / \mathrm{Al}$ zeolite. On the contrary the latter zeolite exhibited slightly higher selectivity towards aromatic hydrocarbons and achieved higher conversion of acids and ketones, a fact related with higher acidic properties. The mesoporosity created after the alkaline treatment tentatively exhibited promising effects on the catalyst's deoxygenation potential. A particularly beneficial effect was observed in the case of the high $\mathrm{Si} / \mathrm{Al}$ zeolite catalyst, where treatment caused a small decrease of organic yield but a pronounced increase of the carbon/oxygen ratio, thus leading to a much higher quality bio-oil.

Catalytic cracking of vacuum gasoil, the current technology for fuel production, could also take advantage of mesoporosity formation in zeolites. Alkaline treated Mordenite were 
additionally acid treated for dealumination and removal of the extraframework debris, thus generating mesopore-modified mordenite samples with very high total acidity. Desilicated and especially desilicated and dealuminated mordenites exhibit higher activity and selectivity towards middle distillates (LCO), while presenting higher olefinicity in gases and higher bottoms conversion. Thus, such modified micro-mesoporous mordenites seem very promising as candidate additives of advanced FCC catalysts for heavier feedstocks.

\section{Acknowledgements}

The financial support of this work by the ACENET COMMON INITIATIVE HECABIO: "HEterogeneous CAtalysis for the Conversion of Solid BIOmass into Renewable Fuels and Chemicals" Project ACE.07.026, is gratefully acknowledged. 


\section{References}

[1] A.V. Bridgwater, Biomass and Bioenergy 2012; 38: 68-94.

[2] Meier, D.; Oasmaa, A.; Peacocke, G. V. C. Properties of Fast Pyrolysis Liquids: Status of Test Methods. In Advances in Thermochemical Biomass Conversion; Bridgwater, A. V., Boocock, D. G. B., Eds.; Blackie Academic \& Professional: London, 1997; p 391.

[3] M. Stöcker, Angew. Chem. Int. Ed. 2008; 47: 9200 - 9211.

[4] H.J. Park, J.K. Jeon, D.J. Suh, Y.W. Suh, H.S. Heo, Y.K. Park, Catal. Surv. Asia 2011; 15: $161-180$.

[5] Huber GW, Iborra S, Corma A. Chem Rev 2006;106:4044-98.

[6] Milne, D.; Agblevor, F.; Davis, M.; Johnson, D. A Review of the Chemical Composition of Fast Pyrolysis Oils from Biomass. In Advances in Thermochemical Biomass Conversion; Bridgwater, A. V., Boocock, D. G. B., Eds.; Blackie Academic \& Professional: London, 1997; p 409.

[7] Piskorz, J.; Majerski, P.; Radlein, D.; Scott, D. S.; Bridgwater, A. V. J. Anal. Appl. Pyrolysis 1998, 46, 15.

[8] Aguado, R.; Olazar, M.; Aguirre, G.; Bilbao, J. Ind. Eng. Chem. Res. 2000, 39, 1925.

[9] Costa, E.; Uguina, A.; Aguado, J.; Hernández, P. J. Ind. Eng. Chem. Process Des. Dev. $1985,24,239$.

[10] Gayubo, A. G.; Ortega, J. M.; Aguayo, A. T.; Arandes, J.M.; Bilbao, J. Chem. Eng. Sci. $2000,55,3223$.

[11] A. Corma, Stud. Surf. Sci. Catal., 1989, 49, 49.

[12] J.C. Groen, J.A. Moulijn, J. Pérez-Ramirez, J. Mater. Chem. 2006, 16, 2121-2131.

[13] D. Verboekend, J. Perez-Ramirez, Catal. Science \& Tecnology 2011, 1, 879-890.

[14] J.C. Groen, L.A.A. Peffer, J.A. Moulijn, J. Pérez-Ramírez, Colloid. Surface. A: Physicochem. Eng. Aspect. 2004, 241, 53-58.

[15] J.C. Groen, R. Caicedo-Realpe, S. Abelló, J. Pérez-Ramirez, Mater. Lett. 2009, 63, 1037-1040.

[16] Y. Tao, H. Kanoh, K. Kaneko, Adsorption 2006, 12, 309-316.

[17] V. Paixao, A.P. Carvalho, J. Rocha, A. Fernandes, A. Martins, Micro and Mesoporous Materials, 2010, 131, 350-357.

[18] M.M. Otten, M.J. Clayton, H.H. Lamb, J. Catal. 1994, 149, 211-222. 
[19] B.T. Carvill, B.A. Lerner, B.J. Adelman, D.C. Tomazack, V.M.W. Sachtler, J. Catal. 1993, 144, 1-8.

[20] M. S. Holm, E. Taarning, K. Egeblad and C. H. Christensen, Catal. Today, 2011, 168, 3.

[21] D. H. Park, S. S. Kim, H. Wang, T. J. Pinnavaia, M. C. Papapetrou, A. A. Lappas, K. S. Triantafyllidis, Angew. Chem. Int. Ed. 2009, 48, $7645-7648$.

[22] Hyun Ju Park, Kyu-Hong Park, Jong-Ki Jeon, Jeongnam Kim, Ryong Ryoo, Kwang-Eun Jeong, Sung Hoon Park, Young-Kwon Park, Fuel 2012, 97, 379-384.

[23] Andrew J. Foster, Jungho Jae, Yu-Ting Cheng, George W. Huber, Raul F. Lobo Appl. Catal. A 2012, 423-424, 154- 161.

[24] Neumann GT, Hicks JC ACS Catal 2012, 2, 642-646.

[25] Mi-Jin Jeon, Seung-Soo Kim, Jong-Ki Jeon, Sung Hoon Park, Ji Man Kim, Jung Min Sohn, See-Hoon Lee and Young-Kwon Park. Nanoscale Research Letters 2012, 7, 18.

[26] D. Verboekend, J. Perez-Ramirez, Catal. Science \& Tecnology 2011, 1, 879-890.

[27] S. Brunauer, P.H. Emmett, E. Teller, JACS, 1938, 60, 309-319.

[28] B.C. Lippens, J.H. de Boer, J. Catal., 1965, 4, 319-323.

[29] E.P. Barrett, L.G. Joyner, P.P. Halenda, JACS, 1951, 73, 373-380.

[30] A. Corma, J. Martínez-Triguero, C. Martínez, J.Catal. 2001, 197, 151-159.

[31] C.A. Emeis, J. Catal. 1993, 141, 347.

[32] R. Castañeda, A. Corma, V. Fornés, J. Martínez-Triguero, S. Valencia, J. Catal. 2006, $238,79-87$.

[33]Clarence D. Chang, Anthony J. Silvestri, J. Catal., 1977, 47, 249-259.

[34] Corma, A., Planelles, J., Sánchez-Marín, J., Tomás, F. J. Catal., 1985, 93 (1), 30-37. 